\title{
Hemarthrosis Caused by Enoxaparin at Patient Presenting with Acute Myocardial Infarction
}

\section{Yunus Emre Okudan* and Hatem Ari}

Department of Cardiology, Faculty of Medicine, Yuzuncu Yil University, Van, Turkey

*Corresponding author: Yunus Emre Okudan, Department of Cardiology, Faculty of Medicine, Yuzuncu Yil University, Van, Turkey, Tel: +90505-922-14-97; E-mail: yunusemreokudan@hotmail.com

Rec Date: Jul 07, 2016, Acc Date: Aug 10, 2016, Pub Date: Aug 17, 2016

Copyright: ( 2016 Okudan YE, et al. This is an open-access article distributed under the terms of the Creative Commons Attribution License, which permits unrestricted use, distribution, and reproduction in any medium, provided the original author and source are credited.

\begin{abstract}
Enoxaparin, a low-molecular-weight heparin, is one of the most useful anticoagulant. Treatment that have large using area including myocardial infarction. In this case a 65 years old male patient presenting with myocardial infarction and hemarthrosis caused by enoxaparin to be told. Patient admitted to the emergency service by angina and referred to us. After the first evaluation he hospitalized because of subacute anterior myocardial infarction. Including liver and renal function tests, platelets were normal. Medical treatment put in order. Enoxaparin was choosing as anticoagulant. During the treatments there was no problem but after last enoxaparin dose oedema was occurred at is left knee. We consulted him to orthopaedics. They did arthrocentesis to determine if it was hematoma or septic arthritis. Complete blood cells count evaluated. WBC 6.1, plt 45, $\mathrm{Hb} 10.6$ detected. So it was hemarthrosis accepted. They recommend elastic bandage, elevation and cold execution. Enoxaparin treatment maintained. The day after oedema regressed. Coronary angiography done and stent implanted. Enoxaparin stopped Oedema followed by daily period, it gone back day by day. After the end of myocardial infarction treatment, he discharged.
\end{abstract}

Keywords: Enoxaparin; Hemarthrosis; Myocardial infarction

\section{Introduction}

Enoxaparin, a low-molecular-weight heparin, is one of the most useful anticoagulant treatments that have large using area including myocardial infarction. Patient who use enoxaparin, factors that increase the risk of bleeding are high doses, advanced age, renal impairment and use of drugs which affect haemostasis at the same time $[1,2]$.

\section{Case Study}

A 65-year-old man admitted to the emergency service by angina and referred to us. Patient evaluated at emergency service then hospitalized because of subacute anterior myocardial infarction. Including liver and renal function tests, platelets were normal. Medical treatment put in order. Enoxaparin was choosing as anticoagulant. During the treatment there was no problem but after last enoxaparin dose oedema was occurred at his left knee. We consulted him to orthopaedics. They did arthrocentesis to determine if it was hematoma or septic arthritis. Complete blood cells count evaluated. WBC 6.1, plt 45 , $\mathrm{Hb} 10.6$ detected. So it was hemarthrosis accepted. They recommend elastic bandage, elevation and cold execution. Enoxaparin treatment maintained. The day after oedema regressed. Coronary angiography done and stent implanted. Enoxaparin stopped. Oedema followed by daily period, it gone back day by day. After the end of myocardial infarct treatment, he discharged.

\section{Discussion}

In our patient concomitant use of antiaggregant drugs can affect haemostasis and cause intraarticular bleeding. However, it occurred approximately 2-3 hour later than enoxaparin injection. So we thought that it was primarily side effect of enoxaparin.

\section{Conclusion}

We aimed to emphasize that hemarthrosis is a rarely side effect of enoxaparin and treatment can go on under orthopaedics suggestion.

\section{References}

1. Montalescot G, Polle V, Collet JP, Leprince P, Bellanger A, et al. (2000) Low molecular weight heparin after mechanical heart valve replacement. Circulation 101: 1083-1086.

2. Levine MN, Planes A, Hirsh J, Goodyear M, Vochelle N, et al. (1989) The relationship between anti-factor Xa level and clinical outcome in patients receiving enoxaparine low molecular weight heparin to prevent deep vein thrombosis after hip replacement. Thromb Haemost 62: 940-944. 